\title{
Fine-Scale Structure Investigation of Nimonic 263 Superalloy Surface Damaged by Femtosecond Laser Beam
}

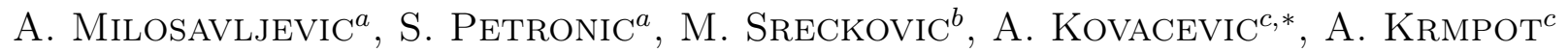 \\ AND K. KOVACEVIC ${ }^{d}$ \\ ${ }^{a}$ Faculty of Mechanical Engineering, University of Belgrade, Belgrade, Serbia \\ ${ }^{b}$ School of Electrical Engineering, University of Belgrade, Belgrade, Serbia \\ ${ }^{c}$ Institute of Physics, University of Belgrade, Belgrade, Serbia \\ ${ }^{d}$ Institute for Ferrous Metallurgy, Niksic, Montenegro
}

\begin{abstract}
Due to the specific conditions of manufacturing, processing and utilization of nickel-base superalloys, the implementation of contemporary precision techniques is necessary in the research of the alloys features. Multi-component nickel-base superalloys, with about of $50 \%$ of nickel content, are commonly exploited in the conditions of high temperatures and pressures as well as in various aggressive operating environments. For successful quality control, which includes the monitoring of the changes in the alloy microstructure, fine-scale structure investigations are necessary. In this work, the samples of nickel-base superalloys have been exposed to $800 \mathrm{~nm}$ femtosecond laser in various operating regimes. Surface damages and dents caused by femtosecond laser pulses have been observed by optical and scanning microscopy.
\end{abstract}

PACS numbers: 01.55.+b, 42.62.-b, 81.05.Bx, 81.20.Vj

\section{Introduction}

The exposition of superalloys to pulsed beams of femtosecond lasers is a contemporary field of research [1, 2]. Superalloys generally consist of: $\gamma$ austenitic matrix, $\gamma^{\prime}$ intermetal compound, $\left(\gamma+\gamma^{\prime}\right)$ eutectic, carbides and topologically close-packed (TCP) phases [3]. Controlled precipitation of the $\gamma^{\prime}$ phase greatly enhances the strength of the Ni-based superalloys [4]. The nimonic series of alloys is distinguished for its excellent high-temperature creep strength and oxidation resistance [5-7].

The interaction between fs beams and many solid-state materials results in the expulsion of particles (nanoclusters, nanoaggregates, atoms and fast ions) from the surface, depending on the processing parameters as well as on the materials characteristics. On surfaces of various metals, fs beam generates nano- and micro-structures as well as laser-induced periodic surface structures (LIPSS) [8], all of which enhance the optical absorption [9]. Thus, laser ablation with fs laser pulses is an interesting technique for the generation of nanostructures and nanoparticles (NPs) of metals and semiconductors, as well as for the deposition of nanoparticle films with peculiar physical properties [10].

\section{Experiment}

The experimental setup (Fig. 1) consists of following parts: a femtosecond laser system, a system for beam

* corresponding author; e-mail:

Aleksander.Kovacevic@phy.bg.ac.yu collimation and focusing, and a system for sample holding and positioning.

The laser system has two lasers: a pump laser (PL), Coherent Verdi V10, and a femtosecond laser (FS), Coherent Mira 900. The pump beam (PB) parameters i.e. the output parameters of the pump laser $\left(\mathrm{Nd}^{3+}: \mathrm{YAG}\right)$ - are: $532 \mathrm{~nm}, 10 \mathrm{~W}$ and $\mathrm{CW}$ regime, while the femtosecond laser beam (FB) parameters - i.e. the output parameters of the femtosecond laser (Ti:sapphire) - are: $800 \mathrm{~nm}, 160 \mathrm{fs}$ of repetition rate and $\approx 30 \mathrm{~nJ}$ per pulse.

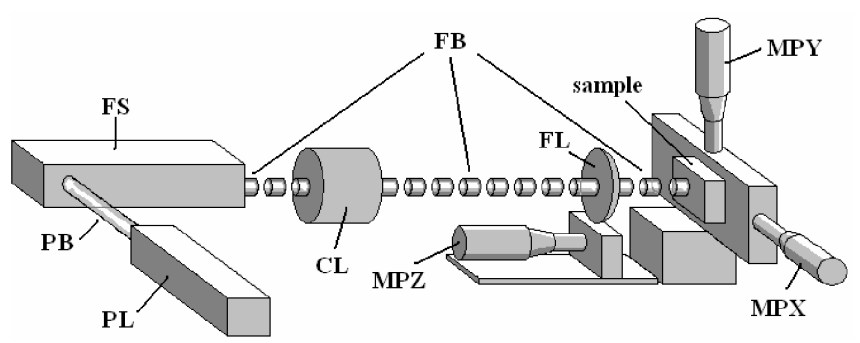

Fig. 1. Experimental setup for the interaction of femtosecond laser beam with a Nimonic 263 sample: PL - pump laser; PB - pump beam; FS - femtosecond laser; FB - femtosecond laser beam; CL - collimating lenses; FL - focusing lens; MPX, MPY, MPZ micropositioners for $x, y$ and $z$ axes.

The system for beam collimation and focusing has two collimation lenses (CL) and one focusing lens (FL) with $5 \mathrm{~mm}$ of focus length, adjusted by micropositioner MPZ. The system for sample holding and positioning adjusts the sample position in two axes, $x$ and $y$, by two micropositioners (MPX and MPY). The sample is Ni- 
monic 263 superalloy, with chemical composition given in Table I [3].

TABLE I

Chemical composition of Nimonic 263 (\% weight).

\begin{tabular}{l|c|c|c|c|c|c|c|c|c|c}
\hline $\begin{array}{c}\text { Element } \\
\text { Alloy }\end{array}$ & $\mathrm{Ni}$ & $\mathrm{Cr}$ & $\mathrm{Mo}$ & $\mathrm{Mn}$ & $\mathrm{Si}$ & $\mathrm{Fe}$ & $\mathrm{C}$ & $\mathrm{Al}$ & $\mathrm{Co}$ & $\mathrm{Ti}$ \\
\hline Nimonic 263 & 50 & 20 & 5.9 & 0.5 & 0.3 & 0.5 & 0.06 & 0.5 & 20 & 2.2
\end{tabular}

The sample used in this experiment has two sections: base material and welded seam. Microhardness measurements, performed on both sections before the irradiation, show higher values of microhardness, of average, for welded seam $\left(271 \mathrm{HV}_{1}\right)$ compared to the base material (232 $\mathrm{HV}_{1}$ ).

The sample has been exposed to fs beam, each exposition bearing different total energy. The energy was altered by changing both the mean output laser power, from 1.170 to $1.820 \mathrm{~W}$, and the exposition time, from 30 to $180 \mathrm{~s}$. The results of microhardness measurement show the increase in microhardness

\section{Results and discussion}

Several regions of the sample, in the weld section, have been irradiated by fs laser beam. The total energy of each exposition varied, depending on both the mean output power of the laser and the exposition time. The values of the fs laser output power and the exposition intervals, linked to the irradiated regions, are given in Table II.

TABLE II

Values of irradiation parameters for Nimonic 263 weld.

\begin{tabular}{c|c|c}
\hline $\begin{array}{c}\text { Irradiated region } \\
\text { No. }\end{array}$ & $\begin{array}{c}\text { Mean output power } \\
{[\mathrm{W}]}\end{array}$ & $\begin{array}{c}\text { Irradiation time } \\
{[\mathrm{s}]}\end{array}$ \\
\hline 1 & 1.234 & 30 \\
2 & 1.260 & 60 \\
3 & 1.170 & 120 \\
4 & 1.820 & 180
\end{tabular}

A photo of irradiated regions of the sample, observed by optical microscope, is presented in Fig. 2. The numbers designating the regions in both Fig. 2 and Table II correspond to each other.

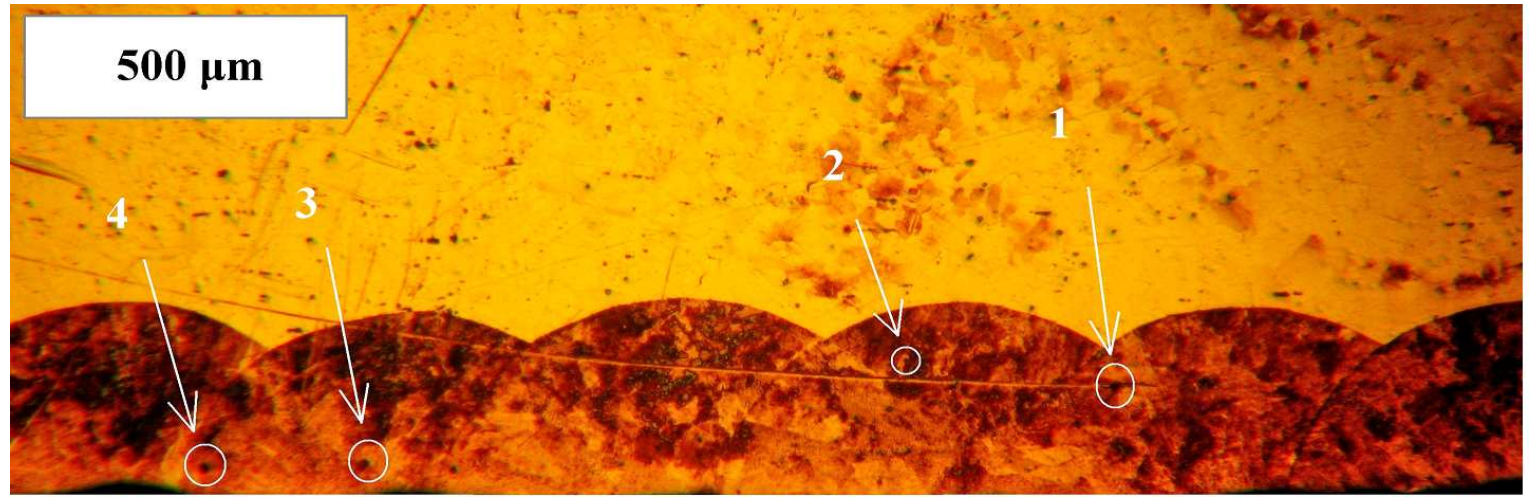

Fig. 2. A photograph of irradiated regions in the weld section of the sample (optical microscope). Horizontal bar in the upper left corner denotes $500 \mu \mathrm{m}$.

A close-up view of regions 2 and 4 is presented in Fig. 3 (optical microscope). The shape of the damages is regular.

More information on the ablated areas is provided by the means of scanning electron microscope - regions 1 and 4 in Fig. 4.

Ablated areas depicted in Fig. 4 have regular shapes and clear rims, due to well-adjusted both the focus and the incident angle of the beam. After the ablation process, the base surface structure of the welded seam has been preserved, which implies that melting has not occurred. Laser pulse duration is shorter than the electron cooling time and the ablation process can be considered as a direct solid-vapor transition [11]. This is an advantageous feature of the interaction between the fs beam and a material; the material evaporates only in the laser beam affected zone (LAZ), which allows very precise and pure laser-processing of metals (and other solids). The occurrence of plasma was not observed during the ablation.

Nanoparticles - with dimensions less than $500 \mu \mathrm{m}$ are noticeable in the ablated areas (Fig. 4), being more numerous in region 1 than in region 4 . The diameter of each ablated area in regions 1 and 4 is estimated at $\approx 14 \mu \mathrm{m}$. Considering the mean irradiation power of the laser to be $1.234 \mathrm{~W}$ (for region 1) and $1.820 \mathrm{~W}$ (for region 4), the average fluence is calculated to $8 \times 10^{5} \mathrm{~W} / \mathrm{cm}^{2}$ and $12 \times 10^{5} \mathrm{~W} / \mathrm{cm}^{2}$, respectively. This is in accordance with the observation that, for increased number of pulses and higher fluences, nanoparticles tend to agglomerate to forms of greater size $[9,12]$. 


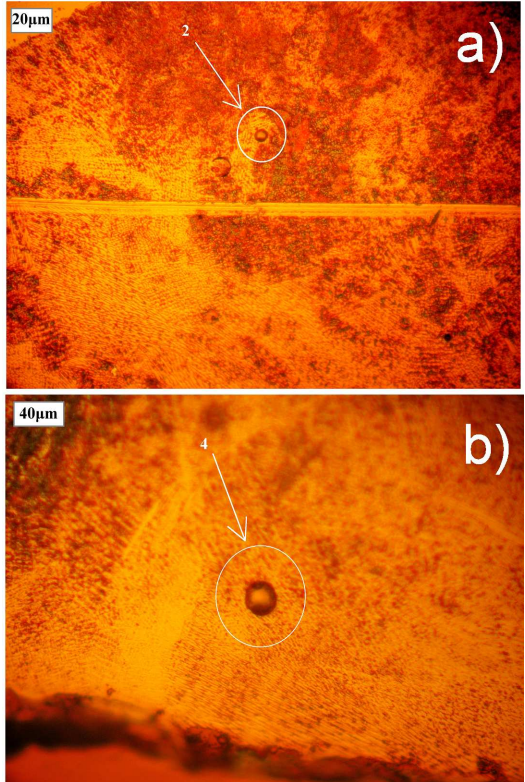

Fig. 3. Photographs of irradiated regions (optical microscope): (a) region 2 (horizontal bar $20 \mu \mathrm{m}$ ); (b) region 4 (horizontal bar $40 \mu \mathrm{m}$ ).
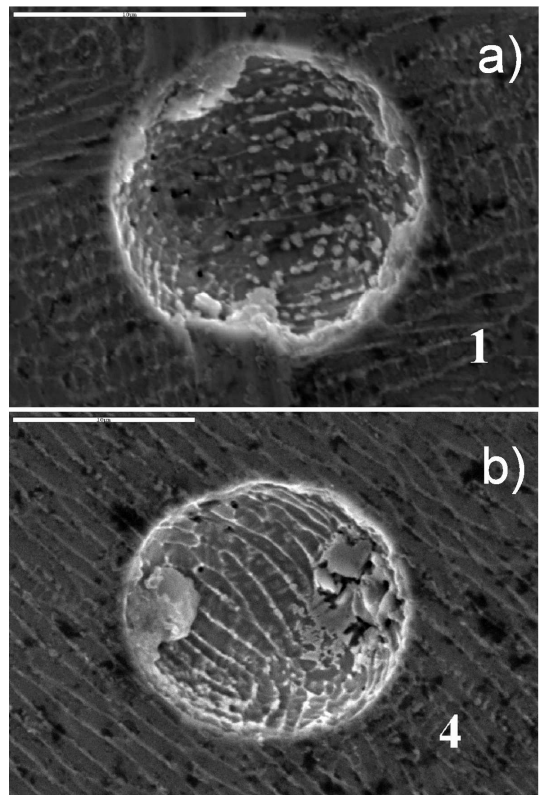

Fig. 4. Micrographs of irradiated regions - ablated areas (scanning electron microscope): (a) region 1; (b) region 4. Horizontal bars in the upper left corners denote $10 \mu \mathrm{m}$.

TABLE III

EDS analysis of region 4 (\% weight).

\begin{tabular}{c|c|c|c|c|c|c|c}
\hline \hline Element & $\mathrm{Al}$ & $\mathrm{Si}$ & $\mathrm{S}$ & $\mathrm{Ti}$ & $\mathrm{Cr}$ & $\mathrm{Co}$ & $\mathrm{Ni}$ \\
\hline ablated area & 0.64 & 0.50 & 1.23 & 5.54 & 19.24 & 18.92 & 53.93 \\
welded seam & 0.38 & 0.24 & 1.71 & 1.97 & 19.51 & 19.27 & 56.91
\end{tabular}

The results of the energy dispersion spectroscopy (EDS) analysis (Table III) show the increase in $\mathrm{Ni}, \mathrm{Al}$ and (especially) Ti contents in ablated areas, which implies the generation of $\mathrm{Ni}_{3}(\mathrm{Al}, \mathrm{Ti})$. The EDS analysis also shows that the content of $\mathrm{Cr}$ and Co remained the same, and could not perceive the presence of Mo and Fe. Bearing that in mind, it can be derived that wavy regions visible at the bottoms of both craters are rafts of $\gamma^{\prime}$ phase (Fig. 4). All commercial Ni-based superalloys have the difference in lattice parameters increased at high temperature due to different coefficient of thermal expansion [13], which leads to $\gamma$-channel forming, $\gamma^{\prime}$ particles coalescence and rafts formation. The morphology and size of $\gamma^{\prime}$ particles changes during the heat treatment: starting from nano $\gamma^{\prime}$ particles, they progress to spheres or cubes, then, to doublet of plates, to octets of cube, then to thin plates and to rafts [14]. The ordered coherent nano $\gamma^{\prime}$ particles shown in Fig. 4 are 20-500 nm size and have spherical shape. It is noticeable that many nano $\gamma^{\prime}$ particles can be found on the surface of rafted $\gamma^{\prime}$ particles. This indicates that finer $\gamma^{\prime}$ particles probably participated from the rafted $\gamma^{\prime}[14]$.

\section{Conclusion}

We have analyzed the interaction of femtosecond laser beam with Nimonic 263 superalloy. Regular shapes of the ablated areas are due to suitable focusing and adjustment of beam parameters. Clear edges and the absence of melted phase indicate the direct solid-vapor transition. The observation that generated nanoparticles agglomerate and that their size increases with both the fluence and the number of pulses is in accordance with the observation that the dimension of $\gamma^{\prime}$ phase increases with the average irradiation power. Therefore, with the increase of total energy nanoparticles congregate to rafts and to forms of higher dimensions - microparticles.

The identification of desired and undesired emerging nano- and microstructures improved usual considerations of surface stability - the resistance to oxidation and corrosion.

\section{Acknowledgments}

The authors would like to thank the Ministry of Science of the Republic of Serbia for kind support under numbers 141003, 141009 and 14067.

\section{References}

[1] N.G. Semaltianos, W. Perrie, P. French, M. Sharp, G. Dearden, K.G. Watkins, Appl. Surf. Sci. 255, 2796 (2008).

[2] N.G. Semaltianos, W. Perrie, P. French, M. Sharp, G. Dearden, S. Logothetidis, K.G. Watkins, Appl. Phys. A 94, 999 (2009).

[3] Metals Handbook, Ed. J.M. Davies, ASM International, 2001. 
[4] G.V.S. Murthy, S. Ghosh, M. Das, G. Das, R.N. Ghosh, Mater. Sci. Eng. A 488, 398 (2008).

[5] P.N. Singh, V. Singh, Scr. Mater. 34, 186 (1996).

[6] N. Srinivasan, Y.V.R.K. Prasad, J. Mater. Proc. Technol. 51, 171 (1995).

[7] M. Maldini, G. Angella, V. Lupinc, Mater. Sci. Eng. A 462, 436 (2007).

[8] B. Tan, K. Venkatakrishnan, J. Micromech. Microeng. 16, 1080 (2006).

[9] K. Paivasaari, J.J.J. Kaakkunen, M. Kuittinen, T. Jaaskelainen, Opt. Express 15, 13838 (2007).

[10] S. Amoruso, R. Bruzzese, X. Wang, N.N. Nedialkov, P.A. Atanasov, J. Phys. D, Appl. Phys. 40, 331 (2007).
[11] B.N. Chichkov, C. Momma, S. Nolte, F. von Alvensleben, A. Tuennermann, Appl. Phys. A 63, 109 (1996).

[12] S. Amoruso, G. Ausanio, A.C. Barone, R. Bruzzese, C. Campana, X. Wang, Appl. Surf. Sci. 254, 1012 (2007)

[13] H. Mughrabi, U. Tetzlaff, Adv. Eng. Mater. 6, 2 (2000).

[14] K. Zhao, Y.H. Ma, L.H. Lou, Z.Q. Hu, Mater. Sci. Eng. A 480, 205 (2008). 